tion gave the following results: 0.1452 , O.I43I, 0.I430, 0.I442, 0.1409 , 0.I433 gram. The average of these determinations is 0.1433 gram. The difference between the results by the two methods is $0.4 \mathrm{mg}$. of manganese. J.t will be noticed, however, that the maximum difference between the results obtained by the phosphate method is $4.3 \mathrm{mg}$., while the corresponding difference for the sulphide method is only $0.7 \mathrm{mg}$.

[CONTRIBUTION FROM THE BUREAU OF CHEMISTRY, DePARTMENT OF AGRICULTURE, No. 56.]

\title{
QUALITATIVE DETECTION OF SACCHARINE IN WINE.
}

By Ed. Mackay Chace.

Received September 28, 1904.

THERE, appeared in a recent issue ${ }^{1}$ of La Revne Commerciale et Coloniale, of Bordeaux, an article by Dr. P. Carles, announcing the discovery of a substance occurring in many French wines which responds to the salicylic acid test for saccharine. In testing for the latter substance by the following method he obtained strong indications of its presence in wines of known purity. Two hundred and fifty cc. of wine were extracted in $50 \mathrm{cc}$. portions with the same $50 \mathrm{cc}$. of ether, the ether evaporated and the extracted matter fused wih solium hydroxide for fifteen minutes. The fused mass was dissolved in water, acidified with sulphuric acid and extracted with low boiling-point gasoline. The gasoline extract was tested for salicylic acid with a dilute solution of ferric alum. In his investigation he used several types of French wines and found the substance in all of them, varying in degree from the red wines to those of the satterne type, which gave the best reactions.

In order to avoid this substance, which he terms "False saccharine," the same writer, in a later publication, ${ }^{2}$ offers a method for testing for saccharine by taste; it is sensitive, however, to but $20 \mathrm{mg}$. per liter.

It has been known for some time that wines extracted by ether alone would respond to the salicylic acid test for saccharine. C. Schmitt ${ }^{3}$ called attention to this fact; he thought the trouble due

I December 12, 1903.

- Abstract in Report de Pharm., No. 3, 1904, p. I10.

3 Report der Anal. Chim., 1887, p. 439. 
to tannin extracted by the ether and proposed the use of a mixture of low boiling-point gasoline and ether. C. Boucher and F. de Bougne $e^{1}$ state that this mixture dissolves traces of tannin and that wines thus extracted still give slight tests. They suggest the use of potassium permanganate for oxidizing the tannin, treating the wine before extraction.

M. Ch. Blarez, a friencl and co-worker of Dr. Carles, has recently published a method, using the same reagent." He evaporates $300 \mathrm{cc}$. of wine with 3 grams of syrup of phosphoric acid until free from alcohol, allows to cool and adds in three portions I5 cc. of a 5 per cent. solution of potassium permanganate. After making $u p$ to the original volume the liquid is extracted in $100 \mathrm{cc}$. portions with the same $100 \mathrm{cc}$. of ether. This method destroys all objectionable substances and, according to the author. is sensitive, testing either by taste or by converting into salicylic acid, to I ing. per liter.

In repeating the above work in this laboratory use was made of some seventy-five samples of French sauternes, clarets, German Rhine wines and California wines of the sauterne type. The method used was that described by Carles, except that the extracted matter was heated with sodium hydroxide at $210^{\circ}$ to $215^{\circ} \mathrm{C}$. for twenty minutes, and that ether was used in place of gasoline for the final extraction. All wines of the sauterne type with one exception gave clear, sharp tests for saccharine. The clarets gave somewhat fainter tests, a few giving none at all. The Rhine wines in most cases gave no test, although some few responded faintly. All the samples had previously been tested in like amounts for salicylic acid with negative results. In many of the wines which gave the heaviest tests for saccharine and which were extracted by the mixture of gasoline and ether. suggested by Schmitt, the salicylic acid was still formed, although the quantity seemed to be somewhat diminished. Anotiner set was cxtracted with ether after precipitation with basic lead acetate, a treatment which should remove all tamin. The samples thus treated all gare inclication of the formation of small amounts of salicylic acid. I few of the above samples. which han given the best tests. Were treated with hide powder, thoroughly shaken, and allowed to stand over night, when they were extracted with ether and treated in the

i bull. Soc. Chim., Paris, 29, 4 t (:90:)

- Abstract in Repont de Pharm. 3, il: 1 itht 
usual manner. When tested for saccharine, traces were still indicated. Several tannin extracts and some samples of commercial tannic acid were extracted and tested, a few of the extracts from oak leaves and bark gave very faint tests, but an extract of pecan shells gave a clear unmistakable test. None of the commercial tannic acids responded in the slightest degree.

It would seen, from this test, while some of the salicylic acid formed may be due to tannin, traces are due to some other substances. Further, that all tannins when fused with sodium hydroxide do not yield salicylic acid, for many wines gave no indication of its formation and the wines which yielded the heaviest tests were those containing but small amounts of tannin.

In destroying the substances which interfere with this test for saccharine it is essential to destroy any salicylic acid which may be present, either naturally or added as a preservative. The two methods already mentioned make use of potassium permanganate at normal temperature. At this temperature that reagent in the writer's hands fails not only to destroy small quantities of added salicylic acid, but only imperfectly removes the substances which form salicylic acid on fusion with sodium hydroxide.

After some little experimenting on the effect of a dilute solution of the reagent at boiling temperature upon the saccharine it was found that the following method was very satisfactory: Fifty cc. of the wine were extracted in the usual manner and the extracted matter, after the evaporation of the ether, re-extracted with gasoline. Whether or not the presence of salicylic acid is indicated, this extract is returned to the dish containing the residue from the extraction with gasoline and the whole made up to about Io cc., I cc. of sulphuric acid ( 1 part in 3 ) added and the solution brought to boiling. If salicylic acid is present, an excess of a 5 per cent. solution of potassium permanganate is slowly added and the boiling continued for one minute. (If salicylic acid is absent the continued boiling is not necessary.) While the solution is still hot a small piece of caustic soda is added and after standing a few minutes the precipitated iron and manganese are filtered off. The filtrate, which should be strongly alkaline, is transferred to a silver crucible lid, evaporated to dryness and heated to from $210^{\circ}$ to $215^{\circ} \mathrm{C}$. for twenty minutes. It is then dissolved in a small quantity of water 
acidified with sulphuric acid ( $I$ part in 3 ) and extracted with ether. The ether extract is tested for salicylic acid with a 0.5 per cent. solution of ferric alum.

'This method was tested on all the samples which had responded to the salicylic acid test for saccharine and in no case was that substance formed after the treatment clescribed.

Repeated trials with wine containing added saccharine showed the method to be sensitive to $5 \mathrm{mgr}$. per liter in the absence of added salicylic acicl. It lestroys the latter substance to the extent of $200 \mathrm{mg}$. per liter and still detects saccharine present to ro $\mathrm{mg}$. per liter.

Since offering this paper for publication, the writer's attention has been called to a method by Villiers, et al, ${ }^{1}$ in which the material to be tested is first clarified with neutral lead acetate and the excess of lead removed by the addition of a sulphate or phosphate, after which the liquid is extracted with benzene. The benzene extract is tested for salicylic acicl. If the taste of this extract leads to the suspicion of the presence of saccharine, it is heated with an excess of potassium permanganate. The fluid is evaporated and heated with $2 \mathrm{cc}$. of sodium hydroxide in a lead-bath for three minutes to $270^{\circ} \mathrm{C}$. It is then dissolved in dilute sulphuric acid and re-extracted with benzene, and the extracted matter tested for salicylic acid. It is the writer's experience that clarification is unnecessary in testing either for saccharine or salicylic acid. In fact, in the presence of only traces of the latter body it is best not to use it. The length of time in which the potassium permanganate is allowed to act upon the extracterl matter is not stated in the abstract. Undoubtedly prolonged heating destroys considerable traces of saccharine. Most methods for the conversion of saccharine into salicylic acid limit the temperature to $250^{\circ} \mathrm{C}$. The writer's experience is that a somewhat lower temperature is sufficient.

1 Alstract in Centralblatt, 1904, p. $14,5 \%$ 